\title{
МЕТРИКИ СИТУАЦИОННОЙ АНАЛИТИКИ В ПЛАТФОРМАХ ВЕБ, ВИДЕО И WI-FI
}

\author{
Азаров Вячеслав Геннадьевич \\ K.т.н., дочент, Арктический государственный \\ агротехнологический университет \\ west_55@inbox.ru \\ Чуприна Марина Васильевна
}

METRICS SITUATIONAL ANALYSTY IN THE WEB, VIDEO AND WI-FI PLATFORMS

V. Azarov

M. Chuprina

Summary. This article gives an analysis of the current platforms of web analytics, situational analytics, Wi-Fi-analysts considered legal and regulatory aspects. Established metrics for each platform, concluded that the possibility of describing web analytics, situational analytics, Wi-Fi-analysts as a separate class of situational analysis and the need for standardization of these platforms as a single class of analytic systems, as well as integrators and aggregators of IT platforms.

The studies can be used in the development of the Russian Federation Technical Committee for Standardization TC164 standard line «Artificial Intelligence», as well as IT integrators and aggregators.

Keywords: web analytics, video content analytics, Wi-Fi analytics, metrics, indicators, software, vendory, regulatory documents.

\section{Ввеление}

B условиях цифрового подхода к финансово-хозяйственной деятельности организаций и последствий проявления спиральной модели жизненного цикла Covid-19, изменяются приоритеты применения ИКТ технологии и принципы ее построения для государственных и муниципальных услуг, бизнес услуг, начинают учитываться возможности агрегации ИТ-систем и платформ с технологиями искусственного интеллекта, расширенной бизнес-аналитикой, статистическими данными удаленных сервисов и услуг, контролем доступа и поведенческой активности населения.

Задачи, решаемые ситуационными аналитиками, в текущих обстоятельствах заключаются в объектив-
Аннотация. В статье выполнен анализ современных платформ веб-аналитики, ситуационной видеоаналитики, Wi-Fi-аналитики, рассмотрены нормативно-правовые аспекты. Установлены метрики для каждой платформы, сделан вывод 0 возможности описания веб-аналитики, ситуационной видеоаналитики, Wi-Fi-аналитики, как отдельного класса ситуационной аналитики и необходимости стандартизации перечисленных платформ, как единого класса аналитических систем, а также интеграторами и агрегаторами ИТ платформ.

Проведенные исследования могут быть использованы при разработке линейки стандартов технического комитета по стандартизации Российской Федерации ТК 164 «Искусственный интеллект», а также ИТ интеграторам и агрегаторам.

Ключевые слова: веб-аналитика, видеоаналитика, Wi-Fi-аналитика, метрики, показатели, программное обеспечение, вендоры, нормативные документы.

ном определении приоритетных метрик и показателей для умного анализа, систематизации больших данных и последующего контроля оценки процессов на основе платформ B2C, ERP, CRM, BI, Al, DSS, Advanced Analytics. Кроме того, исследование метрик на основе статистического анализа в рамках предпроектного обследования процесса, позволит найти наиболее весомые и, таким образом, обосновать экономическую целесообразность необходимого и достаточного инструментария ситуационной аналитики для реализации процесса, или сформировать техническое задание на агрегацию существующей и аналитической платформы, с оценкой себестоимости решения.

Наиболее актуальными платформами ситуационной аналитики с точки зрения тождественных признаков 
по архитектурным и программно-техническим критериям являются такие решения как веб-аналитика, ситуационная видеоаналитика, Wi-Fi-аналитика, которым и посвящена настоящая работа.

Основной гипотезой данной работы является положение о возможности описания веб-аналитики, ситуационной видеоаналитики, Wi-Fi-аналитики как отдельного класса ситуационной аналитики.

\section{Цель исслеАования}

Цель исследования заключается в определении общих метрик ИТ платформ на основе веб-аналитики, ситуационной видеоаналитики, Wi-Fi-аналитики, для подтверждения выдвинутой гипотезы.

\section{Материалы и результаты исслеАований}

Веб-аналитикой принято считать систему измерения, сбора, анализа, представления и интерпретации информации о посетителях веб-сайтов с целью улучшения и оптимизации последних. Показатели веб-аналитики условно классифицируются на целевые экономические и неэкономические показатели. Нормативно-правовых документов, описывающих классификацию, правила применения и условия эксплуатации непосредственно ПО (программное обеспечение) веб-аналитики на территории Российской Федерации не предусмотрено.

Неэкономические метрики, или индикаторы КРI (Кеу Performance Indicators) включают, по данным различных отечественных и зарубежных источников и ИТ-аналитиков от 8 и выше динамических показателей, и обеспечивают возможность ситуационного анализа поведенческой активности по группам параметрических характеристик. При этом видится актуальным включение в состав метрик факторов конкуренции поисковых систем и SEO (Search Engine Optimization) [1], расширения рынка SEO, актуализации вопросов межъязыковых аспектов SEO [2] и борьбы с бот-трафиком, методик выбора KPI для SEO продвижения.

К основным экономическим показателям веб-аналитикии относят показатели интернет-маркетинга: конверсию, стоимость привлечения СРС (Cost Per Click), стоимость лидов CPL (Cost Per Lead), возврат маркетинговых инвестиций (ROMI), коэффициент брошенных корзин (CAR) и другие. Общее количество главных показателей варьируется. Так, по мнению [3], показатель доходности ROMl является основным критерием группы экономических показателей; по данным источника [4], возможна конверсия показателей коммуникационной активности в экономические критерии и их ранжирование; суще- ствуют и другие подходы определения веса экономических показателей, и определение приоритетных.

С точки зрения практической реализации, используются программные средства и комплексы, основанные на счетчиках, специализированное программное обеспечение и анализаторы лог-файлов.

Актуальны следующие решения, основанные на счетчиках для классических и облачных структур: Яндекс.Метрика, GoogleAnalytics, OpenStat, Livelnternet, Open Web Analytics, Finteza, Adobe Analytics и другие. Стоимость владения и поддержки существенно отличается. Бесплатными и условно бесплатными решениями являются Open Web Analytics, Яндекс.Метрика, а также в базовом варианте GoogleAnalytics, Deep Log Analyzer и другие. Решения на коммерческой основе, как правило, распространяются в вариантах оплаты ежемесячного тарифа и поставки коробочного комплекта ПО.

Помимо ПО комплексного анализа и веб-аналитики, может применяться узкоспециализированное ПО сквозной аналитики для В2B и В2С и платформ на их основе. К ним можно отнести, ConveadRoistat, Calltouch, Mixpanel и другие системы мониторинга поведения пользователей на электронных торговых площадках. В части анализа логов следует отметить, что структура лог-журнала, например шлюза к компановке бюджетного решения может отличаться от аналогичного решения основанного, например, на серверных группировках, гипервизорах или SAN-фабриках. Как правило, лог-файл импортируется в табличные процессоры или анализаторы лог-файлов. К последним относятся решения The webalizer, Weblog expert, Spylog Flexolyzer. Для облачных хранилищ применяюся Cloud-based Log Analyzer, Loggly, SumoLogic, Splunk, Papertrail, Logz.io и другие. Отдельные анализаторы имеют исполнение для мобильных приложений. Независимую оценку системам веб-аналитики и топ-листы решений приводят различные отечественные СМИ и аналитические агентства (Habr.com, Vc.ru, Texterra.ru и другие), при этом ранговые оценки Топ-листов не всегда равноценны, отсутствуют обоснования выбора и критерии оценки.

Прикладному ПО на основе веб-аналитики уделяют внимание не только специалисты сферы SEO, но и подразделения обеспечения информационной безопасности, такие как Cybersecurity, Security Research, SOC, Fraud Analyst, а также регуляторы ИКТ, что связано с вопросами трансляции персональных данных (ПД) во внешние базы данных, передачи Javascript и РНР-трекеров координат, cookies, ID пользователей, MAC и IP-адресов [5, 6,7]. Таким образом, можно сделать вывод о системах веб-аналитики, как технологии loB (Internet of Behaviors), поэтому определением веб-аналитики следует считать: 
разновидность ІоВ технологий направленную на сквозную аналитику действий пользователей Интернет и мобильных приложений.

Для веб-аналитики, предполагается оценивать следующие показатели: критерии цчелевой аудитории, подмножество экономических показателей КРI, критерии IоB, критерии защчищенности персональных данных.

Видеоаналитика имеет несколько отличающихся друг от друга формулировок, что можно сравнить на примерах определений источников $[8,9]$. Согласно [8], видеоаналитика (VCA, Video Content Analysis) - компьютеризированная обработка и автоматический анализ потокового видеоряда, который поступает на видеосервер от видеокамер, носимых устройств и устройств Интернета вещей ІоT, оснащенных веб-камерами. Согласно [9], видеоаналитика - программное обеспечение, реализующее алгоритмы автоматизированного получения различных данных на основании анализа последовательности изображений, поступающих с видеокамер в режиме реального времени или из архивных записей. С точки зрения авторов работы каждое из определений требует внесения изменений в части включения в определение аппаратно-программных комплексов, а также указаний на контроль доступа к системам видеоаналитики. Однако более точное определение приводит источник [9].

Ситуационная видеоаналитика образовалась в процессе развития технологий СКУД (система контроля и управления доступом) и видеонаблюдения и, согласно [9] «эволюционирует от классических детерминированных алгоритмов обработки изображений к когнитивным технологиям на базе искусственного интеллекта, позволяющим восстанавливать контекст происходящего на сцене видеонаблюдения». Видеоналитика решает задачи распознавания и идентификации лиц, объектов, действий, событий и позволяет формировать пространственную и планарную геолокацию. В основе программного обеспечения лежит комплекс алгоритмов ВІ, машинного зрения, машинного и глубокого обучения, позволяющих вести умный видеомониторинг и производить анализ видеоряда без прямого участия человека. Видеоаналитику связывают с международными стандартом Европейского союза ONVIF (Open Network Video Interface Forum) описывающим передатчик сетевого видео, аналитику сетевого видео, хранилище сетевого видео и клиентов сетевого видео, отечественным стандартом ГОСТ Р 59385-2021, приводящим классификационные признаки и сцены наблюдения, методическими рекомендациями $\mathrm{P}$ 78.36.030-2013, отдельные аспекты рассматриваются ГОСТ Р 51241-2008 и Ф3-123 [9, 10, 11, 12].
Немаловажным фактором стандартизации систем видеоаналитики и соответственно, правил ее проектирования и эксплуатации в России, является публикация в 2021 г. ГОСТ Р 59385-2021. Стандарт имеет доминанты для применения видеоаналитики в государственном сегменте для решения АПК «Безопасный город» и меньшей степени крупном бизнесе, что очевидно из перечня вводимых ГОСТ определений и понятий. Ожидаемо продолжение линейки стандартов видеоаналитики технического комитета по стандартизации ТК 164. Как видится, для полноценной стандартизации систем видеоаналитики в последующей линейке стандартов, потребуется стандартизация и описание: правил интеграции видеоаналитики в корпоративные платформы; описание ключевых KPI метрик и показателей; условий защиты персональных данных от утечек по техническим каналам; компонентных структур систем видеоаналитики и дружественных архитектур.

Условно, системы ситуационной видеоаналитики можно разбить на два подкласса: ситуационная видеоаналитика в концепциях АПК «Безопасный город» (системы умной охраны правопорядка, Smart Polic) и прикладная видеоаналитика хозяйствующих субъектов.

В первом случае, координатором развития систем и подсистем ситуационной видеоаналитики на всех вертикалях управления является МЧС России [13]. К нормативно-правовым документам, определяющим правила и порядок эксплуатации систем видеоаналитики, относятся федеральные законы 16-Ф3, 152-Ф3 [14, 15], Концепции «Безопасный город» [13], Постановление Правительства РФ № 969 [16] и ряд других нормативных документов федерального и регионального уровней. Перечисленные нормативно-правовые документы регламентируют типы объектов видеонаблюдения, требования к функциональным свойствам технических средств идентификации и обнаружения тревожных ситуаций, транспортной безопасности, паспорт безопасности объекта и категории потенциальной опасности, правила сертификации, а также технические параметры структурированных кабельных сетей. На федеральном уровне сформирована единая государственная система предупреждения и ликвидации чрезвычайных ситуаций и происшествий с органами управления в кризисных ситуациях, Национальным центром управления в кризисных ситуациях и Центрами управления в кризисных ситуациях на региональном уровне. Региональная архитектура предполагает агрегацию данных Центра обработки данных (ЦОД), центра обработки вызовов Единой дежурно-диспетчерская службы с сегментами данных регионального и муниципального уровней, систем фото-видеофиксации нарушения правил дорожного движения и наружнего видеонаблюдения, протоколов передачи данных MPLS (MultiProtocol Label Switching) 
и других технологий на основе криптографических протоколов. По данным источнка [17], в систему могут быть интегрированы решения до 150 различных по функциональным характеристикам систем. Все программно-технические решения подлежат обзательной сертификации по стандартам ФСТЭК и ФСБ.

Интеграция федеральной и региональной системы видеоаналитики из хранилищ ЦОД в частный бизнес не предусмотрена, область работы ситуационного аналитика ограничено допусками МЧС, МВД, ФСБ и других участников оперативного взаимодействия.

Во втором случае, программно-аппаратные платформы ситуационной видеоаналитики могут применяться в качестве интеллектуальных инструментов бизнес-процессов. В первую очередь, видеоаналитика актуальна для отраслей, где необходимо обеспечить контроль доступа, распознавание лиц, детекцию движения, поведения, проникновения, слежения, распознавание номер автомашин, выполнение маркетинговых исследований в торговле и других вариативных направлений анализа видеоданных. В особую категорию потенциальных потребителей VCA могут входить запросы услуг бенчмаркинга.

Сегодня, происходит локационная миграция систем хранения данных (СХД) архивов видеоаналитики в облачные ресурсы и цОД. К таким решениям можно отнести, например, решения на основе VSaaS (Video Surveillance-as-a-Service) и программ для управления видео Video Management System (VMS), а также Intelligent Video Surveillance (IVS). Классическое видеонаблюдение и контроль доступа с применением биометрических параметров также могут быть консолидированы с ПО, например, в известные решения Интеллект (компания ITV), SecurOS (компания ISS), XProtect (компания Milestone) и другие.

Интеграция сцен видеонаблюдения допустима в ERP, CRM, BI и другие платформы, что подтверждается успешной реализацией ряда проектов отечественных вендоров и интеграторов (Лига Цифровой экономики, Крок, Parma TG), и зарубежного сегмента интеграторов (Tableau, Power Bl, Qlik). По разным источникам, к ведущим отечественным вендорами систем видеоаналитики ISS, Vocord, Macroscop, Ларга.Видеосервер, Видеоинтеллект, а также платформами описанным источником [9], присоединяются поставщики локальных решений для видеонаблюдения, мониторинга и детекции. Например, крупнейший поставщик систем персональной видеофиксации для МВД и Росгвардии БайтЭрг планирует интегрировать мониторинг и фиксацию правонарушений средствами индивидуальных камер Dozor 78 в служебные системы распознавания лиц, системые интеграторы акцентируют внимание на возможностях интеграции видеопотока при помощи SDK (Software Development Kit) от производителя ПО или открытых протоколов управления и получения событий. Именно перечисленные аспекты, смещают приоритеты систем видеонаблюдения в сторону искусственного интеллекта и глубокого обучения.

Приоритетным экономическим критерием видеоаналитики является стоимость детектора за один канал. Другие показатели оценивают капиталовложения в архитектуру, сопровождение и услуги интеграции в принятых горизонтах планирования. Внедрение видеоаналитики требует дополнительных затрат для организации СХД на местах, что приводит к удорожанию решения. Однако линейка коробочных решений на основе встроенной видеоаналитики в IP-камеры и облачных сервисов позволяет снизить финансовые нагрузки для частного бизнеса. Кроме того, отдельные вендоры, включая Samsung, Panasonic предлагают открытые платформы, что обеспечивает сторонним разработчикам возможность дополнять камеры новыми интеллектуальными функциями [18]. Следует отметить благоприятные возможности для компаний сегмента услуг laaS (Infrastructure-as-a-Service) и VSaaS в части предоставления аренды или развертывания ИТ инфраструктуры с интеллектуальными IP-камерами под условия технического задания заказчика. Рынок услуг laaS и VSaaS для видеонаблюдения предоставляют Ростелеком, Invideon, MTC и другие провайдеры, и частные компании.

Обзор систем видеонаблюдения и видеоаналитики, представлен в различных источниках и аналитических материалах компаний IDC, Mordor Intelligence, Discovery Research Gro, MarketsandMarkets, Omdia, Гротек и других. При этом, очевидно значительное расхождение результатов анализа этого рынка, что требует дополнительного исследования и верификации результатов открытых источников.

Оценка систем видеонаблюдения и аналитики предложены TAdviser [19], оценка производительности видеоаналитики ограничивается i-LIDS тестом (не утвержден гОСТ России) [10].

Таким образом, для оценки систем видеоаналитики предлагается оценивать: критерии иелевой аудитории,, подмножество экономических показателей KPI, критерии технических требований к системам и средствам идентификачии физических лиц, критерии технических требований $к$ системам и средствам обнаружения тревожных ситуаций, критерий производительности, глубину интеграции с системами СКУД, глубину интеграции с аналитическими платформами, критерии IaaS и VSaaS, кри- 
терии уровней сертификации, критерии защчищченности персональных данных.

Wi-Fi-аналитика. Wi-Fi-аналитика или аналитика местоположения делает сравнительный анализ географического положения объектов наблюдения по периодам, локациями, зонам внутри локации, характеристикам оконечного оборудования объектов наблюдения и отдельные характеристики персональных данных. На выходе ПО системы, ситуационные аналитики получают аналитические отчеты в виде графиков и диаграмм для заданного временного интервала. По сути, Wi-Fi-аналитика является технологией IoB и относится к классу ВІ решений. Нормативно-правовых документов описывающих классификацию, правила применения и условия эксплуатации непосредственно ПО и телекоммуникационного оборудования Wi-Fi-аналитики на территории Российской Федерации не предусмотрено.

В отличие от веб-аналитики, решение требует капиталовложений в телекоммуникационную структуру, средства вычислительной техники и программное обеспечение. В минимальную конфигурацию комплекса Wi-Fi-аналитики должны входить Wi-Fi-радар, несущая, выделенный сервер, программное обеспечение.

Объект наблюдения оказывается в зоне действия Wi-Fi-сети, при этом мобильное устройство автоматически передает МАС-адрес. МАС-адрес в свою очередь транслируется в базу данных сервера платформы в хешированном виде. Процесс сбора МАС-адресов зачастую является скрытым, за исключением маркетинговых промоакций с раздачей Wi-Fi, когда собираются данные специально настроенными роутерами Wi-Fi-радарами, или так называемыми Wi-Fi-ловушками, которые сканируют окружение и видят мобильные устройства на расстоянии определяемом мощностью радара, при этом объекту наблюдения не обязательно иметь подключение к Wi-Fi. Сформировав базу MAC-aдресов, возможно посредством «Яндекс.Директ» отправить таргетированную рекламу объектам, которые ранее были замечены в конкретном магазине [20], а также организовать sms и бот рассылки по уникальным идентификаторам.

Как правило, Wi-Fi-аналитика позволяет получать и анализировать следующие типы метрик: частота посещений, время нахождения в точке геолокации; маршруты движения посетителей; вовлеченные посетители; лояльные посетители; перекрестные посещения; социальные профили посетителей; производители мобильных устройств посетителей. В перспективе или по мере необходимости, возможна интеграция с системами СКУД.
По данным Orange Business Services основными производители Wi-Fi-аналитики для российского сегмента являются НПО Аналитика (Retail Instruments), Cisco Syctems Inc, Kinian, РосБизнесСофт. На внешнем рынке по данным 360Quadrants лидуруют ПО следующих компаний: Aptilo SMP Wi-Fi, Blix Traffic, Блум Интеллект, Cisco Systems Inc [21]. Wi-Fi-аналитика, может использовать алгоритмы машинного обучения и быть интегрирована в B2C, ERP, CRM, BI, DSS, Advanced Analytics платформы.

Основными рисками для объектов наблюдения при использовании Wi-Fi-аналитики являются возможность несанкционированного доступа к персональным данным или иной информации позволяющей установить личность. Для европейских стан и разработчиков Wi-Fi-аналитики в сегменте, действует Общий регламент по защите персональных данных (GDPR), который вступил в силу в 2018 году. Российские требования отличаются от европейских в части нормативно-правовой базы и определяются 152-Ф3, рядом нормативных документов ФСТЭК и других распорядительных документов регуляторов ИКТ, поэтому капиталовложения в проектное решение может потребовать применения специализированных и сертифицированных аппаратно-программных мощностей, а также алгоритмов анонимизации.

Для оценки систем Wi-Fi-аналитики предлагается оценивать: критерии целевой аудитории, подмножество экономических показателей KPI, глубину интеграции с аналитическими платформами, критерии уровней сертификации, критерии защуищенности персональных данных.

\section{Выво $\triangle \mathrm{b}$}

В результате проведенного анализа, установлены метрики веб-аналитики, ситуационной видеоаналитики, Wi-Fi-аналитики. Метрики могут применяться для количественной и качественной оценки экономических и неэкономических показателей. Метрики видеоаналитики являются универсальными и имеют общие признаки (за исключением отдельных показателей) и таким образом, рассмотренные платформы возможно описать как отдельный класс систем ситуационной аналитики с единой системой измерения.

С точки зрения права, требуется выработать единый подход к стандартизации, правил эксплуатации и обеспечению безопасности ПД рассмотренных платформ, как единого класса тождественных систем. Проведенные исследования могут быть использованы при разработке линейки стандартов технического комитета по стандартизации Российской Федерации ТК 164 «Искусственный интеллект». 


\section{ЛИТЕРАТУРА}

1. Тагаров Б.Ж. Развитие рынка поисковой оптимизации в России//Креативная экономика. — 2018. - T. 12, № 9. — c. 1373-1384. — URL: https:// cyberleninka.ru/article/n/razvitie-rynka-poiskovoy-optimizatsii-v-rossii (дата обращения 21.10.2021)

2. Ачкасов А.В. Межъязыковые аспекты поисковой оптимизации // Известия Российского государственного педагогического университета им. А.И. Герцена.— 2021.— № 199.—142-149.

3. Демкина 0.В. Анализ возможности использования веб-аналитики в управлении доходностью организации / Демкина 0.В., Марушко Л.Ю. // Московский экономический журнал. - 2019.— № 9.— C. - 785-793.— URL: https://cyberleninka.ru/article/n/analiz-vozmozhnosti-ispolzovaniya-veb-analitiki-vupravlenii-dohodnostyu-organizatsii (дата обращения 20.10.2021)

4. Коваленко А.Е. Преобразование показателей оценки экономической эффективности технологий интернет-маркетинга в малом бизнесе //Вестник Южно-Уральского государственного университета. Серия: Экономика и менеджмент. - 2020. — Т. 14, № 2.—C. 158-163.

5. Google обвинили в незаконном сборе данных и пригрозили штрафом $\$ 5$ млрд.—URL: https://www.rbc.ru/technology_and_media/03/06/2020/5ed790e49 а7947813766с80е (дата обращения 23.10.2021)

6. РКН: Использование аналитики может привести к блокировке сайта.— URL: https://habr.com/ru/post/433714 (дата 0бращения 23.10.2021)

7. Google Analytics в мобильных приложениях как угроза нацбезопасности или почему госорганы плюют на ФCTЭК и Pockoмнадзор. - URL: https://www. securitylab.ru/blog/personal/Business_without_danger/350181.php (дата обращения 23.10.2021)

8. Видеоаналитика, термины, сферы применения, технологии Video Content Analysis.— URL: https://www.tadviser.ru/index.php/Статья: Видеоаналитика_ (термины,_сферы_применения,_технологии) (дата обращения 23.10.2021)

9. ГОСТ Р 59385-2021. Информационные технологии. Искусственный интеллект. Ситуационная видеоаналитика. Термины и определения описаны термины, понятия, типовые ситуации: национальный стандарт Российской Федерации: издание официальное: утвержден и введен в действие Приказом Федерального агентства по техническому регулированию и метрологии от 5 марта 2021 г. № 120-ст: введен впервые: дата введения 2021-09-01 / разработан 000 «Видеоинтеллект».— Изд. официальное.- Москва: Стандартинформ, 2021. - 10 c.

10. Р 78.36.030-2013. Применение программных средств анализа видеоизображения в системах охранного телевидения в целях повышения антитеррористической защищенности ПЦО подразделений вневедомственной охраны. Методические рекомендации: утверждены и введен в действие ГУВО МВД России от 02.12.2013: дата введения 01.01.2014 / разработан ФКУ НИЦ «Охрана» МВД России. — Москва: НИЦ «0храна», 2013. — 237 с.

11. ГОСТ Р 51241-2008. Средства и системы контроля и управления доступом. Классификация. Общие технические требования. Методы испытаний: национальный стандарт Российской Федерации: издание официальное: утвержден и введен в действие Приказом Федерального агентства по техническому регулированию и метрологии от 17 декабря 2008 № 430-ст: дата введения 2009-09-01 / разработан Федеральным государственным учреждением Научно-исследовательский центр «Охрана» (ФГУ НИЦ «Охрана») МВД России, Центром оперативного руководства деятельностью вневедомственной охраны (ЦОРДВО) МВД России и Всероссийским научно-исследовательским институтом стандартизации и сертификации в машиностроении (ВНИИНМАШ).Изд. официальное. - Москва: (тандартинформ, 2009. - 28 с.

12. Федеральный закон от 24.04.2020 № 123-Ф3 (последняя редакция) «0 проведении эксперимента по установлению специального регулирования в целях создания необходимых условий для разработки и внедрения технологий искусственного интеллекта в субъекте Российской Федерации — городе федерального значения Москве и внесении изменений в статьи 6 и 10 Федерального закона «0 персональных данных» (Bступ. в силу с 24.04.2020).— URL: http://kremlin.ru/acts/bank/45475 (дата обращения: 23.10.2021).

13. Распоряжение Правительства РФ от 03.12.2014 № 2446-р (ред. от 05.04.2019). 06 утверждении Концепции построения и развития аппаратно-программного комплекса «Безопасный город».— URL: https://docs.cntd.ru/document/420238601 (дата обращения: 23.10.2021).

14. Федеральный закон от 09.02.2007 № 16-Ф3 (ред. от 11.06.2021) «0 транспортной безопасности» (с изм. и доп., вступ. в силу с 01.07.2021).— URL: http:// www.kremlin.ru/acts/bank/24993 (дата обращения: 23.10.2021).

15. Федеральный закон от 27.07.2006 № 152-Ф3 (ред. от 30.12.2020) «0 персональных данных» (с изм. и доп., вступ. в силу с 01.03.2021).— URL: https:// legalacts.ru/doc/152_FZ-o-personalnyh-dannyh/ (дата обращения: 05.05.2021).

16. Постановления Правительства РФ от 26.09.2016 г. № 969 (ред. от 17.04.2021) 06 утверждении требований к функциональным свойствам технических средств обеспечения транспортной безопасности и Правил обязательной сертификации технических средств обеспечения транспортной безопасности. URL: https://docs.cntd.ru/document/420377376 (дата обращения: 23.10.2021).

17. Рапоряжение Правительства. М.: Департамент образовательной и научно-технической деятельности МчС России.— URL: https://apkbg.info/tajmlajn/ rasporyazhenie-pravitelstva/ (дата обращения: 23.10.2021).

18. Видеоаналитика на практике.— URL: https://www.osp.ru/lan/2015/03/13045265 (дата обращения: 23.10.2021).

19. Видеонаблюдение (рынок России).—URL: https://www.tadviser.ru/index.php/Статья: Видеонаблюдение_(рынок_России) (дата обращения: 23.10.2021).

20. Карлос. А. Большой брат смотрит на тебя. Ив твой кошелек. —URL: https://marketmedia.ru/media-content/totalnaya-slezhka/ (дата 0бращения:23.10.2021).

21. Best Wi-Fi Analytics Software. Comparing 24 vendors in Wi-Fi Analytics Software across 24 criteria. — URL: https://www.360quadrants.com/software/wi-fianalytics-software (дата обращения: 23.10.2021). 